\title{
Articulação dos atores institucionais no desenvolvimento da agricultura familiar no Sudoeste Goiano
}

\author{
JOSÉ LUIS GOMES DA SILVA \\ Universidade de Taubaté \\ MARCIA MARIA DE PAULA \\ Centro Universitário de Mineiros - UNIFIMES
}

\section{Resumo}

Nos últimos anos a agricultura familiar no Brasil tem tomado novas dimensões. A discussão permeia o meio acadêmico e no campo político programas de fomento são criados. $O$ estudo analisou a articulação dos atores institucionais que fazem parte do processo de desenvolvimento da agricultura familiar no Município de Mineiros, na região do Sudoeste Goiano. Foi utilizada a abordagem qualitativa e formulários padrão para o registro das instituições e ações. Utilizou-se a pesquisa documental a partir de dados obtidos junto às agências e bancos de dados ligados a agricultura familiar no Município de Mineiros-Goiás e região, durante o período de 1996, ano de criação do Programa Nacional de Fortalecimento da Agricultura Familiar-PRONAF a 2014. Nos resultados, identificou-se 32 instituições ligadas à agricultura familiar, representantes do governo, instituições de ensino superior, cooperativas, associações rurais, instituições financeiras, empresas privadas e organizações não-governamentais, desenvolvendo ações extensionistas, de assistência técnica e de pesquisa. Com o estudo concluiu-se que existe uma rede de cooperação local, desenvolvendo ações nas dimensões social, econômica, ambiental e cultural da sustentabilidade. As informações adquiridas poderão subsidiar ações locais e regionais na implementação das políticas públicas direcionadas para o setor da agricultura familiar.

Palavras-chave: Planejamento e desenvolvimento regional. Atores institucionais. Agricultura familiar.

\section{Interaction of actors in institutional development of family farm in Southwest Goiano}

\author{
Abstract \\ In recent years the family farming in Brazil has taken new dimensions. The discussion \\ permeates academia and the political field development programs are created. The study \\ analyzed the articulation of institutional actors that are part of the process of development \\ of family farming in the county of Mineiros in the Southwest Goiás region. Qualitative \\ approach and standard forms for the registration of institutions and actions was used. We
}



Goiano

used documentary research from data obtained from agencies and databases connected to family farming in the county of Goiás and Mineiros-region, during 1996, the year of creation PRONAF to 2014. In the results, we identified 32 institutions involved in family farming, government representatives, higher education institutions, cooperatives, rural associations, financial institutions, private companies and non-governmental organizations, developing extension actions, technical assistance and research. In the study it was concluded that there is a network of local cooperation, developing actions in the social, economic, environmental and cultural sustainability. The information acquired may subsidize local and regional implementation of public policies towards family farming sector actions.

Keywords: Planning and regional development. Institutional actors. Family farming.

\section{Articulación de los actores institucionales en el desarrollo de la agricultura familiar en el Sudoeste Goiano}

Resumen

En los últimos años la agricultura familiar en Brasil ha tomado nuevas dimensiones. La discusión abarca el medio académico y en el campo político los programas de fomento se crean. El estudio analizó la articulación de los actores institucionales que forman parte del proceso de desarrollo de la agricultura familiar en el municipio de Mineiros, en la región del Sudoeste Goiano. Se utilizó el enfoque cualitativo y los formularios estándar para el registro de las instituciones y acciones. Se utilizó la investigación documental a partir de datos obtenidos en las agencias y bancos de datos ligados a la agricultura familiar en el municipio de Mineiros-Goiás y región, durante el período de 1996, año de creación del PRONAF a 2014. En los resultados, en el caso de las instituciones de enseñanza superior, cooperativas, asociaciones rurales, instituciones financieras, empresas privadas y organizaciones no gubernamentales, desarrollando acciones extensionistas, de asistencia técnica y de investigación. Con el estudio se concluyó que existe una red de cooperación local, desarrollando acciones en las dimensiones social, económica, ambiental y cultural de la sostenibilidad. Las informaciones adquiridas podrán subsidiar acciones locales y regionales en la implementación de las políticas públicas dirigidas al sector de la agricultura familiar.

Palabras clave: Planificación y desarrollo regional. Actores institucionales. Agricultura familiar.

\section{Introdução}

O desenvolvimento de uma região está pautado numa série de fatores, entre eles as condições naturais, as políticas governamentais, a participação popular e a interação das organizações populares com as instituições públicas e as esferas de governo. No Brasil, discutir o desenvolvimento, especificamente o desenvolvimento rural, é fundamental em razão da centralidade que a agricultura e a pecuária ocupam nas relações sociais e econômicas em grande parte do País.

A dimensão continental no Brasil se apresenta com desigualdades sociais e regionais marcantes (IPEA, 2010). O País é visto, no cenário mundial, como um grande celeiro na produção de alimentos. Isso foi confirmado nos últimos anos, principalmente pela eficácia do agronegócio da agricultura empresarial (REIFSCHNEIDER et al., 2010; SILVA, 1998). Porém, a agricultura familiar, em muitas regiões, ainda apresenta dificuldades em se estabelecer enquanto atividade produtiva e geradora de renda (XAVIER et al., 2007).

No presente estudo, compreende-se que o desenvolvimento rural, assim como o desenvolvimento na sua amplitude, vai além das questões econômicas. Diante desse contexto, Abramovay (2000) aborda que o desenvolvimento numa região ou num país não é sinônimo de expansão da área produzida ou da produção, ou seja, o desenvolvimento rural não se reduz ao crescimento agrícola. O autor 
aborda ainda que as regiões agrícolas desenvolvidas caracterizam-se por uma rede de relações entre os atores sociais envolvidos, onde o resultado se traduz em um ambiente favorável a empreendimentos inovadores.

O termo agricultura familiar começa a ser difundido no Brasil em meados da década de 1990 e tem sido alvo de muitos estudos no meio acadêmico e na criação de políticas públicas. Vale ressaltar que uma das últimas políticas públicas do governo federal que mobilizou de forma significativa o setor diz respeito à obrigatoriedade de adquirir produtos da agricultura familiar para a alimentação escolar por meio da lei n. 11.947 de 2009 (TRICHES; SCHNEIDER, 2010, 2012).

O Censo Agropecuário 2006, divulgado pelo Instituto Brasileiro de Geografia e Estatística-IBGE em 2009 aponta a importância da agricultura familiar na economia brasileira. No Brasil, existem 4.367.902 estabelecimentos agropecuários familiares, o que corresponde a $84,4 \%$ do número de estabelecimentos rurais do País. Embora ocupe apenas $24,3 \%$ da área total destinada à produção, a agricultura familiar responde por $38 \%$ da renda bruta gerada no meio rural e ocupa $74,4 \%$ do pessoal que trabalha no campo. São 12,3 milhões de pessoas trabalhando na agricultura familiar. A cada 100 ha, a agricultura familiar ocupa 15,3 pessoas, contra 1,7 da agricultura empresarial. Outro aspecto importante na produção da agricultura familiar é o abastecimento interno, que contribui, mesmo que marginalmente, na pauta de exportações. A agricultura familiar é responsável pela produção da maior parte dos alimentos que chegam diariamente à mesa dos brasileiros (FRANÇA; DEL GROSSI; AZEVEDO MARQUES, 2009).

Com o estabelecimento das políticas de apoio à agricultura familiar a partir da década de 1990, torna-se necessário discutir a relevância social e econômica desse segmento para a economia brasileira e ainda o seu papel estratégico com vista a um modelo de desenvolvimento mais inclusivo e sustentável.

Dessa forma, buscar meios para entender como se dá a dinâmica da agricultura familiar na dimensão local e regional é fundamental para compreender o desenvolvimento. E, partindo da concepção que a cooperação está inserida nos processos de desenvolvimento, é importante conhecer quais são os atores sociais envolvidos nos processos de fortalecimento do setor.

Partindo dessa reflexão, o objetivo desse estudo é analisar e discutir o processo de desenvolvimento da agricultura familiar no Município de Mineiros, no estado de Goiás, a partir da articulação dos atores institucionais, situado na região do Sudoeste Goiano e comparada a outras regiões do estado e do País, é uma região rica e próspera.

\section{Atores institucionais no desenvolvimento}

Partindo da concepção que a cooperação está inserida nos processos de desenvolvimento (BANDEIRA, 1999; RAMBO; FILIPPI, 2009; AGNE; WAQUIL, 2011; ANDRADE, LUCENA GOMES, CÂNDIDO, 2012; RODRIGUES et al., 2012), torna-se necessário conhecer de que forma os atores sociais e institucionais estão inseridos nesses processos. Conhecer a articulação das instituições e a necessidade do entendimento de uma abordagem mais sistêmica são aspectos cada vez mais relevantes na busca do entendimento dessas relações. 
No presente estudo, o termo Instituição se refere a todas as organizações, associações, representações de classe, sindicatos e órgãos públicos que existem na localidade e cujas ações são voltadas para a defesa e a promoção dos interesses de um determinado grupo social ou de uma parcela de sua população (MULS, 2010). No caso em questão, a agricultura familiar.

Muls (2010) faz a análise de alguns conceitos da área de economia institucional que são úteis para o estudo das experiências de desenvolvimento endógeno. Aborda ainda o conceito de capital social e o entendimento da importância da formação de redes entre os organismos e instituições locais, que podem contribuir positivamente para o avanço do debate sobre desenvolvimento.

Em sua obra, Higgins (2005) discute os fundamentos teóricos do capital social. Inicia sua discussão refletindo como algumas sociedades, a cooperação e a autogestão permitem atingir o desenvolvimento de forma rápida e eficiente, contrapondo a outras, em que a corrupção e o individualismo permeiam as práticas culturais. Apresenta ainda o capital social como o quinto fator de produção, juntamente com a terra, trabalho, capital físico e capital humano. Aborda que os fatores econômicos não vão muito longe se as pessoas não são capazes de gerir os recursos com espírito de cooperação e compromisso com os objetivos comuns.

De acordo com Muls (2010), vários autores discutem o conceito de capital social sob diferentes enfoques. O primeiro a discutir o tema foi Pierre Bourdieu (1980). Ele procurou mostrar o conceito como a construção de uma rede durável de relações que permitiria ao indivíduo (ou grupo) associar um capital que estivesse fora do circuito econômico, mas que este mesmo capital (cultural e social) poderia ser usado para a acumulação e a reprodução social. Bourdieu (1980) aborda ainda que o capital social é o conjunto de relações que podem ser mobilizados efetivamente para beneficiar o individuo ou a sua classe social, ou seja, ele permite às pessoas mais êxito na competição social.

Outro autor que discute o tema e o popularizou no Brasil, fazendo uma série de pesquisas em campo, foi Robert Putnam (PUTNAM, 2002). Ele se refere ao capital social como as práticas sociais, normas e relação de confiança que existem entre cidadãos de uma sociedade, sendo entendido também como um conjunto de crenças compartilhadas que melhora o desempenho dos estados democráticos. Os sistemas de participação que estimulam a cooperação como confiança, ajuda mútua, reciprocidade, solidariedade, foram mostrados nos seus estudos como variáveis de desenvolvimento.

Dallabrida (2006) discute que o desenvolvimento conta com a dimensão tangível, material (traduzida principalmente nos aspectos econômicos), e a dimensão intangível, ou seja, imaterial. Essa segunda dimensão refere-se à capacidade coletiva para realizar ações de interesse da sociedade. Além de considerar o capital social dentro dessa perspectiva, o autor aborda também conceitos correlatos, tais como os de capital sinergético e densidade institucional, aliado a questão do empoderamento. Partindo dessa reflexão, ele considera necessário aprofundar a ação do Estado, com sua prática de governar, na contribuição de geração ou aumento do estoque de capital social numa região ou território.

Dessa forma, identificar e analisar a dimensão intangível do desenvolvimento, ou seja, a rede de relações entre as instituições que acontecem, é 
importante nos processos de desenvolvimento de uma região. Torna-se necessário identificar se essas redes se colaboram no sentido de valorizar e potencializar o ambiente na busca de melhorias para a coletividade. Assim, quando o capital social está presente em uma sociedade e as instituições cumprem o seu papel, toda comunidade se beneficia, pois as tomadas de decisão, a implantação das ações, são feitas de forma colaborativa.

\section{Agricultura Familiar no Brasil e Desenvolvimento Sustentável}

O termo agricultura familiar começou a ser difundido no Brasil na década de 1990 com a criação do Programa Nacional de Fortalecimento da Agricultura Familiar-PRONAF. Essa terminologia, com roupagem nova, diz respeito ao pequeno agricultor, lavrador e, no Brasil, vem acompanhada de uma série de medidas governamentais e a criação do Ministério do Desenvolvimento Agrário-MDA.

Wanderley (1999, p. 21) apresenta o conceito de "[...] agricultura familiar como aquela em que a família, ao mesmo tempo em que é proprietária dos meios de produção, assume o trabalho no estabelecimento produtivo". A autora ainda faz uma reflexão apontando que a agricultura familiar não é uma nova categoria social dentro da Sociologia Rural. Porém, nos últimos anos, no Brasil, vem com ares de novidade e renovação, sendo um personagem diferente do camponês tradicional, que teria assumido sua condição de produtor moderno. Entretanto, esse agricultor mantém muitos traços desses camponeses e ainda enfrenta muitos desafios em face à modernização da agricultura brasileira.

Abramovay (2012) aborda que o agricultor familiar, diferentemente do camponês tradicional, assume a condição de produtor moderno integrado ao meio social e econômico, incorporando os avanços tecnológicos. Discute ainda as particularidades do setor no ambiente econômico.

A I, no seu primeiro artigo, estabelece os conceitos, princípios e instrumentos destinados à formulação das políticas públicas direcionadas à Agricultura Familiar e Empreendimentos Familiares Rurais (BRASIL, 2006). Define Agricultura Familiar como uma forma de produção onde predomina a interação entre gestão e trabalho, sendo os agricultores familiares que dirigem o processo produtivo, com ênfase na diversificação e utilizando o trabalho familiar, eventualmente complementado pelo trabalho assalariado (BRASIL, 2006).

No Brasil, os empreendimentos da agricultura familiar, além dessa denominação e caracterização descrita acima, ainda são classificados como microempreendedores individuais, que são pessoas que trabalham por conta própria e que se legalizam como pequeno empresário (PORTAL DO EMPREENDEDOR, 2014). Essa categoria, conforme estabelece a legislação, é acionada quando o agricultor agrega valor à sua produção, com o processamento dos seus produtos. Isso se torna uma exigência para acessar os mercados formais.

$\mathrm{Na}$ análise bibliométrica de Roder e Silva (2013), mapeando as teses de doutorado no Brasil sobre agricultura familiar, no período de 2000 a 2009, foram identificadas 153 teses sobre o tema. Destas, a maioria foram estudos feitos nas Regiões Sul e Sudeste do País (110 trabalhos), seguida pela Região Nordeste, com 23 teses, Região Centro-Oeste, com 13 e Região Norte com 6. Em relação à temática, a maioria (122 teses) tratava de assuntos relacionados mais diretamente ao 
Articulação dos atores institucionais no desenvolvimento da agricultura familiar no Sudoeste Goiano

desenvolvimento rural. Sobressaíram as abordagens a respeito das ações, das políticas e dos atores, voltadas para o desenvolvimento rural.

A discussão sobre o desenvolvimento rural permeia também a relação cidade-campo, que nos últimos anos passou por transformações (SILVA; DEL GROSSI; CAMPANHOLA, 2002; MONTE-MÓR, 2006).

Silva, Del Grossi e Campanhola (2002) relatam os resultados do Projeto Rurbano: caracterização do Novo Rural Brasileiro, que teve por objetivo analisar as transformações nas relações urbano-rural, discutindo alguns velhos mitos como o que prega que o espaço rural é sinônimo de atraso. Outras questões abordadas no estudo foram a pluriatividade, as rendas agrícolas e não agrícolas, a proximidade da produção com a indústria e as atividades não agrícolas ligadas à moradia, ao lazer e à prestação de serviços.

Monte-Mór (2006) faz uma discussão na relação campo-cidade na atualidade, abordando que apesar de legalmente no Brasil, as cidades serem definidas pelos perímetros urbanos, essa fronteira é cada vez mais difusa e de difícil identificação.

Rodolfo Hoffmann (2001, 2011), em suas pesquisas, relaciona a estrutura fundiária com a elevada desigualdade de distribuição de renda no Brasil. Hoffmann (2011) observa ainda que não há indicações que demonstram mudanças substanciais na distribuição de posse da terra e na distribuição da renda agrícola nos últimos anos no Brasil. Menciona também que os programas de transferência de renda e o crescimento real do salário mínimo tiveram impacto positivo na redução da desigualdade na renda do Brasil no período de 1995 a 2009.

Silva, Gomés e Castañeda (2010) analisaram oito países na América Latina que tiveram como base os diferentes modelos de desenvolvimento do setor agropecuário e os impactos sobre os níveis de pobreza rural. No processo de industrialização desses países, a agricultura teve um papel subordinado. Esta subordinação foi representada pela produção a preços que permitiram aos setores urbanos ter acesso aos alimentos com salários compatíveis com a capacidade de remuneração da indústria que nascia. Isso explica que os governos aplicaram políticas que fixaram preços aos produtos agropecuários alimentícios em um nível relativamente baixo, e explica também o lento crescimento da produção agropecuária. O estabelecimento desse modelo significou o abandono, por parte dos governos, da preocupação pelo desenvolvimento rural.

A Política de Desenvolvimento do Brasil Rural, coordenada pelo MDA, incorporou a abordagem territorial como base conceitual de sua formulação e implementação (BRASIL, 2013). E, alinhado a isso, nas políticas de desenvolvimento regional, a premissa é pensar a região na dimensão do território ou um sistema local, conforme abordado por (MORAES 2003).

Partindo de um cenário de complexidade e multifacetário, entende-se que a articulação dos atores institucionais se apresenta como premissa na busca do desenvolvimento sustentável. Cita-se o exemplo de Bandeira (1999), que faz uma reflexão sobre o desenvolvimento em algumas regiões no Brasil a partir de práticas participativas visando ao desenvolvimento regional. $O$ autor descreve e analisa experiências de participação da sociedade civil em face à problemática e às políticas de promoção do desenvolvimento regional. Essas práticas revelam-se importantes na formulação e na implementação de políticas públicas. 
A definição da Agricultura e Desenvolvimento Rural Sustentado foi primeiramente apresentada em uma reunião da Organização das Nações Unidas para a Alimentação e Agricultura-FAO, em Den Bosh em 1991 (GIORDANO, 2000). A partir daí, a questão da sustentabilidade na agricultura começou a ser discutida em face ao modelo instalado no pós-guerra, década de 1950. Pouco dependente e bastante depredatória dos recursos naturais, esse modelo não considera a dinâmica dos fatores que interagem no meio produtivo.

O modelo industrial agroquímico adotado no pós-guerra, período conhecido como Revolução Verde, está sendo repensado na agricultura familiar e vem gradativamente sendo substituído por modelos com princípios da agroecologia. Apesar dos ganhos da modernização da agricultura, o problema da fome, por exemplo, não foi solucionado. Esse fato demonstrou que o problema não se deve a uma produção insuficiente de alimentos, e sim à má distribuição de renda e à desigualdade social, que impedem o acesso ao alimento. Por outro lado, a implantação da agricultura industrial demanda o uso intensivo de agrotóxicos, cujos efeitos negativos à saúde humana e ao ambiente são evidentes (ZIEMBOWICZ et al., 2007; NAVOLAR; RIGON; PHILIPPI, 2010).

Atualmente, a agricultura familiar vem ganhando novos ares graças às políticas públicas instituídas e o suporte do meio acadêmico com a realização de pesquisas nas múltiplas dimensões que o setor está inserido (MATTEI, 2005; SCHNEIDER, 2010).

Sachs (2009, p. 39), na sua obra "Caminhos para o desenvolvimento sustentável”, lista prioridades de pesquisas para o Brasil. Entre elas, "[...] o estudo de sistemas de produção integrada, adaptados às condições locais, deve prosseguir em diferentes escalas de produção, desde a agricultura familiar aos grandes sistemas comerciais [...]". Indica ainda a necessidade de buscar a modernização das técnicas empregadas pela agricultura familiar de subsistência.

Diante do exposto, ressalta-se que os modelos de agricultura praticados pela agricultura industrial não são compatíveis com as características da agricultura familiar (BALSAN, 2006; ZIEMBOWIC et al., 2007). Nesse modelo, a principal característica é o monocultivo, desconsiderando a diversidade inerente ao modelo familiar. Nesse contexto, observa-se que agricultura familiar está relacionada diretamente às múltiplas dimensões da sustentabilidade. Quanto ao prisma das dimensões econômica e social, ela é geradora de renda e trabalho e também está intimamente ligada aos aspectos culturais, à segurança alimentar, à diversidade na produção e à valorização do ambiente.

\section{Método}

O presente estudo é descritivo, na medida em que se analisa e se discute a articulação dos atores institucionais que fazem parte do processo de desenvolvimento da agricultura familiar no Município de Mineiros na região do Sudoeste Goiano. A abordagem do objeto é qualitativa, uma vez que, para Richardson (1999), as análises terão por base o conhecimento teórico-empírico que permite aferir cientificidade ao tema estudado.

De acordo com Bauer e Gaskell (2008), a abordagem qualitativa nas pesquisas sociais lida com a interpretação das realidades. Os autores ainda fazem 

Goiano

uma discussão acerca do viés qualitativo e quantitativo, destacando que não há quantificação sem qualificação e nem análise estatística sem interpretação. Aborda também que na abordagem qualitativa há um pluralismo no processo da pesquisa, que vai além do instrumento.

O estudo utilizou a pesquisa documental como procedimento técnico. Godoy (1995) afirma que, no enfoque qualitativo, a pesquisa documental é utilizada e representa uma forma que pode colaborar, de forma inovadora, com contribuições importantes no estudo de diferentes temas. A autora ressalta ainda que os documentos constituem uma fonte não reativa, visto que permanecem ao longo do tempo. No entanto, nesse tipo de estudo, três aspectos devem ser observados com atenção: a escolha dos documentos, o acesso a eles e a sua análise.

No presente estudo, as primeiras fontes consultadas foram os sítios das agências e bancos de dados oficiais (PNUD, IBGE, Portal ODM, MDA, EMATER e entidades parceiras) para obter informações sobre a agricultura familiar no Município de Mineiros-Goiás e na região. A caracterização da região e dos agricultores familiares na pesquisa se deu principalmente nos bancos de dados oficiais do IBGE e nas informações de documentos disponibilizados pelas instituições locais.

Para identificar os atores sociais locais e as ações realizadas no período do estudo, a busca foi realizada nos relatórios de atividades da EMATER, que são encaminhados ao poder público municipal ao final de cada ano. Pesquisou-se nos livros de ata do Comitê Municipal do PRONAF/Conselho Municipal de Desenvolvimento Rural, no Núcleo de Estudos e Pesquisa em Agroecologia do Centro Universitário de Mineiros e na cooperativa. Também foram pesquisados documentos nos relatórios e materiais do Programa de Extensão Universitária de Apoio à Agricultura Familiar-PROEAF do Centro Universitário de Mineiros UNIFIMES. Foram consultadas ainda, publicações resultantes dos projetos de pesquisa, além de outros materiais relativos às ações desenvolvidas. A Empresa de Assistência Técnica e Extensão Rural-EMATER é o órgão do governo do estado que atua diretamente com os agricultores familiares. Os principais documentos avaliados nesse órgão foram os relatórios de atividades da EMATER.

Após a identificação dos atores institucionais e a seleção dos documentos, elaborou-se a linha do tempo, a partir da homologação da Lei do PRONAF em 1996 até o ano 2013. O objetivo foi identificar as ações e a atuação dos atores institucionais nessas ações, podendo assim interpretar e analisar como se dá a interação entre os esses atores envolvidos no processo de desenvolvimento sustentável, analisando a dimensão social, econômica, ambiental e cultural.

$\mathrm{Na}$ fase de coleta de dados, foi utilizado um formulário de registros que contou com duas partes. Primeiro, foram identificados os atores institucionais e, posteriormente, as ações (dimensões social, econômica, ambiental e cultural da sustentabilidade) voltadas para o fortalecimento da Agricultura no Município de Mineiros(GO).

A partir dos dados obtidos, pôde-se categorizar as informações dentro da dimensão social, econômica, ambiental e cultural, conforme a descrição de Sachs (2009), e ainda subsidiar as inferências, análises e discussões acerca da articulação dos atores institucionais em favor do desenvolvimento da agricultura familiar na região. 


\section{Resultados e Discussão}

O Município de Mineiros (GO) situa-se na região do Sudoeste Goiano e possui uma população de 52.935 habitantes, de acordo com o censo do IBGE de 2010. A economia da região está diretamente ligada à atividade agropecuária, inicialmente com a pecuária extensiva e posteriormente, a partir de 1970, com a chegada dos sulistas na região, com a produção de grãos, soja e milho principalmente. A agricultura empresarial é voltada para a produção de grãos, pecuária, avicultura integrada e cana-de-açúcar, e a agricultura familiar é representada por comunidades de agricultores tradicionais, quilombolas e assentados, que, na sua grande maioria, produzem leite em escala comercial (EMATER, 2013).

Em relação à caracterização física e biológica, a região está situada numa área de grande importância ambiental. O município abriga uma das maiores áreas contínuas preservadas de cerrado: o Parque Nacional das Emas, patrimônio natural reconhecido pela Organização das Nações Unidas para a Educação, a Ciência e a Cultura-UNESCO, em 2002. Em se tratando dos recursos hídricos, ressalta-se que, na região, encontram-se as nascentes de rios que drenam três grandes bacias hidrográficas do continente Sul-americano (região divisora de águas): Bacia da Prata, Bacia Amazônica e Bacia do Paraguai (Pantanal Mato-grossense), além de ser área de carga e recarga do Aquífero Guarani (PAULA et al., 2008).

O município integra o Território Rural de Identidade Parque das Emas que é composto por nove municípios da região do Sudoeste Goiano, que são: Aparecida do Rio Doce, Aporé, Chapadão do Céu, Jataí, Mineiros, Perolândia, Portelândia, Santa Rita do Araguaia e Serranópolis.

Da mesma forma, os dados apresentados pelo Censo da Agricultura Familiar, realizado em 2006, mostram que o Estado de Goiás conta com 88.436 estabelecimentos rurais familiares, correspondendo a $65,2 \%$ do total dos estabelecimentos rurais do País, ocupando uma área de $13 \%$. No Município de Mineiros (GO), a agricultura familiar representa $43 \%$ do total de estabelecimentos rurais e $7 \%$ da área total ocupada. Os dados demonstram que, não diferente do Brasil, há uma concentração da área na agricultura não familiar.

Analisando os índices de desenvolvimento dos municípios que compõem a região do Município de Mineiros (GO), observa-se que a região encontra-se com valores de médio a alto desenvolvimento, considerando o Índice de Desenvolvimento Humano Municipal (IDHM), 2010 (PNUD; FJP; IPEA, 2013).

Mas mesmo apresentando esses dados, a concentração da riqueza é grande e parcela significativa da comunidade se encontra em situação marginal. De acordo com o Portal ODM no Acompanhamento Municipal dos Objetivos de Desenvolvimento do Milênio, no Objetivo 1 - "Acabar com a Fome e a Miséria", o município de Mineiros-Goiás teve a participação dos 20\% mais pobres da população na renda passou de 2,9\%, em 1991, para 3,9\%, em 2010, diminuindo os níveis de desigualdade. Em 2010, a participação dos 20\% mais ricos era de 59,8\%, ou seja, 15 vezes superior à dos $20 \%$ mais pobres (PORTAL ODM, 2013). 
Articulação dos atores institucionais no desenvolvimento da agricultura familiar no Sudoeste Goiano

O IDHM é um indicador que permite conhecer a realidade de cada município, trazendo a possibilidade de comparação entre regiões. Permite-se extrapolar a dimensão puramente econômica e a partir da perspectiva do desenvolvimento humano, amplia o debate na formulação de políticas, que de fato levarão à melhor qualidade de vida (PNUD; FJP; IPEA, 2013).

Comparando aos índices do Estado de Goiás, o sudoeste goiano é considerado uma região rica e próspera. As cidades que compõem o território rural apresentaram índices de desenvolvimento - IDHM - em 2010 se situando entre 0,654 a 0,757 , considerados de médio a alto (Tabela 3). Comparando o IDHM Renda, IDHM Longevidade e IDMH Educação, entre os municípios, observa-se que houve avanço em todas as dimensões, porém o maior desafio é a educação, que ainda se encontra com índices baixos.

\subsection{As Instituições da Agricultura Familiar no Município de Mineiros (GO)}

O desempenho das políticas públicas em fortalecer a agricultura familiar por meio do PRONAF principalmente, tem demonstrado o esforço dos governantes. Mesmo assim, observa-se que os agricultores familiares em Goiás e no Município de Mineiros ainda enfrentam uma série de problemas no sentido de se estabelecerem economicamente. Essa realidade pode ser percebida nos assentamentos, comunidades quilombolas e propriedades de agricultores familiares tradicionais. Muitas famílias apresentam dificuldades em se estabelecerem produtivamente, enfrentando problemas como a baixa rentabilidade que gera desmotivação, sensação de exclusão e ainda dificuldades de segurança alimentar e nutricional (EMATER, 2013).

No presente estudo, o objetivo foi entender como se dá a articulação dos atores institucionais no enfrentamento dessas dificuldades, ou seja, na promoção do desenvolvimento sustentável da agricultura familiar. Nesse contexto, a EMATER e o Sindicato dos Trabalhadores Rurais de Mineiros deram início, a partir de 2002, a uma articulação entre os atores sociais locais visando à realização de uma série de ações voltadas para a promoção do desenvolvimento local da agricultura familiar. Inicialmente, por meio da disponibilização de recursos via crédito rural, cursos de capacitação, realização de encontros e seminários e a criação de uma cooperativa de crédito da agricultura familiar. No primeiro momento, o foco foi a promoção da utilização do crédito do PRONAF.

No presente estudo, pôde-se observar que ao longo do período avaliado, ou seja, da criação do PRONAF em 1996 até 2013, trinta e duas instituições estiveram envolvidas numa série de ações voltadas para o fortalecimento da agricultura familiar. Dallarida (2006), Rambo e Filippi (2009) abordam a densidade institucional, aliado à questão do capital social. Pode-se ver ao longo do tempo, a participação das mesmas instituições, ora de forma direta, ora indireta, demonstrando reciprocidade e cooperação, elementos básicos no entendimento de capital social (PUTNAM, 2002). 
Os atores institucionais que estiveram envolvidos com a agricultura familiar no Município de Mineiros (GO), são representantes do governo, instituições de ensino superior, cooperativas, associações rurais (agricultores familiares tradicionais, assentados e quilombolas), instituições financeiras, empresas privadas, organizações não governamentais, instâncias colegiadas, sindicatos e outros.

Em relação ao governo, destaca-se a EMATER, órgão do governo do Estado de Goiás que tem como público alvo os agricultores familiares e os representantes do governo municipal, Prefeitura e Câmara Municipal. Técnicos da Companhia Nacional de Abastecimento-CONAB e MDA têm contribuído com ações ligadas ao Programa de Aquisição de Alimentos-PAA e ao Território Rural de Identidade Parque das Emas, respectivamente. A Empresa Brasileira de Pesquisa AgropecuáriaEMBRAPA está presente em muitas ações. As instituições de ensino superior, UNIFIMES, Faculdade Mineirense-FAMA e Universidade Federal de Goiás (UFG), também merecem destaque, promovendo e participando em uma série de ações.

Observou-se que a maioria das instituições é de abrangência local, seguido pela atuação das instituições presente da região, seguido pelas instituições de abrangência nacional. A atuação desses atores indica a presença de uma rede local de cooperação em torno da agricultura familiar.

Rambo e Filippi (2009) afirmam a necessidade da participação e do protagonismo dos atores locais nas ações que visam ao desenvolvimento da agricultura familiar, atendendo as suas demandas, necessidades e interesses. Enfoca que é o empoderamento da sociedade civil que tem marcado positivamente os processos de desenvolvimento territorial em muitas regiões. Aliado a isso, o capital social, governança, enraizamento e participação social são temas inerentes nessa discussão. Trabalhos como os de Agne e Waquil (2011) e Abramovay, Magalhães, Schroder (2010) que apontaram a participação ativa de atores sociais nos processos de desenvolvimento da agricultura familiar, demonstram que a inclusão produtiva, o acesso aos mercados se darão a partir desse exercício.

Gastal et al. (2009) discutem o construir coletivo, no qual as pesquisas nas ciências agrárias, voltadas para a agricultura familiar não devem ser no sentido de construir um pacote tecnológicos. A proposta é relacionar a complexidade que envolve as diferentes dimensões do desenvolvimento sustentável no campo tecnológico, os sistemas produtivos; no campo social, os processos organizativos; no campo econômico, a inserção no mercado; e no campo ambiental, a conservação dos recursos naturais.

Assim, a interação entre atores institucionais em torno de um objetivo comum, ou seja, o desenvolvimento propicia a tornar o processo mais participativo e mais adequado à realidade social, econômica, política, cultural e ambiental de cada localidade.

\subsection{Ações de promoção do desenvolvimento sustentável da agricultura familiar e a articulação dos atores institucionais no Município de Mineiros (GO)}

A agricultura familiar no Município de Mineiros (GO) conta com uma rede de cooperação local. Essa rede, com a cooperação de instituições regionais e nacionais, propiciou a consecução de algumas ações, que alavancaram outras e que foram 
fundamentais para dar suporte às políticas públicas implantadas a partir da década de 1990.

Com a elaboração da linha do tempo, pôde-se identificar as instituições e as ações voltadas para o fortalecimento da agricultura familiar. Dada natureza dessas ações, elas foram caracterizadas como ações extensionistas, de assistência técnica e ações de pesquisa. Essas últimas, em menor frequência.

$\mathrm{Na}$ análise das ações, partiu-se dos princípios da sustentabilidade descrito por Sachs (2009), considerando as dimensões da sustentabilidade social, econômica, ambiental e cultural.

Nos documentos analisados, a interpretação e análise foram feita baseadas no objetivo de cada ação. Considerando que muitas ações foram realizadas por mais de uma instituição, a fonte documental pode ser uma ou mais, visto que a mesma ação pode estar descrita em mais de um documento.

Diante do exposto, entende-se que a agricultura familiar, muita mais que uma forma de produção, é uma forma de vida, que traz nas suas múltiplas funções, bens não mercantilizados, como a proteção de bens culturais e ambientais. Sen (2010, p. 44) argumenta que o desenvolvimento econômico na forma que está inserido na atualidade pode "[...] ser danoso a um país, já que pode conduzir à eliminação de suas tradições e herança cultural. Objeções desse tipo são com frequência sumariamente descartadas com o argumento de que é melhor ser rico e feliz do que pobre a tradicional". O autor ainda comenta na mesma obra (p. 50): "Se um modo de vida tradicional tem de ser sacrificado para escapar-se da pobreza devastadora ou da longevidade minúscula (que é como vivem muitas sociedades tradicionais há milhares de anos), então são as pessoas diretamente envolvidas que têm de ter a oportunidade de participar do que deve ser escolhido".

Diante disso, cabe aos atores institucionais que atuam no planejamento das políticas de desenvolvimento, adquirirem uma postura democrática e estabelecerem rumos que atendam às reais necessidades e potencialidades de uma região.

Desta forma, de acordo com as ações identificadas, pode-se observar que houve a participação de várias instituições e de alguma forma elas se interrelacionaram, formando uma rede de cooperação com o objetivo de atingir uma dimensão, seja social, econômica, ambiental ou cultural.

A Figura 1, a seguir, mostra um fluxograma que identifica no centro as instituições dos agricultores (associações e cooperativas). Gravitando no entorno, estão os atores institucionais parceiros atuando nas ações ligadas às dimensões social, econômica, ambiental e cultural da sustentabilidade. Essa rede de cooperação atua nas ações que estão diretamente envolvidas com as necessidades básicas da sociedade, que é a produção de alimentos. 
Figura 1. Rede de Cooperação formada entre as instituições de Mineiros(GO), com ações voltadas para o desenvolvimento sustentável da agricultura familiar -

fevereiro/2013

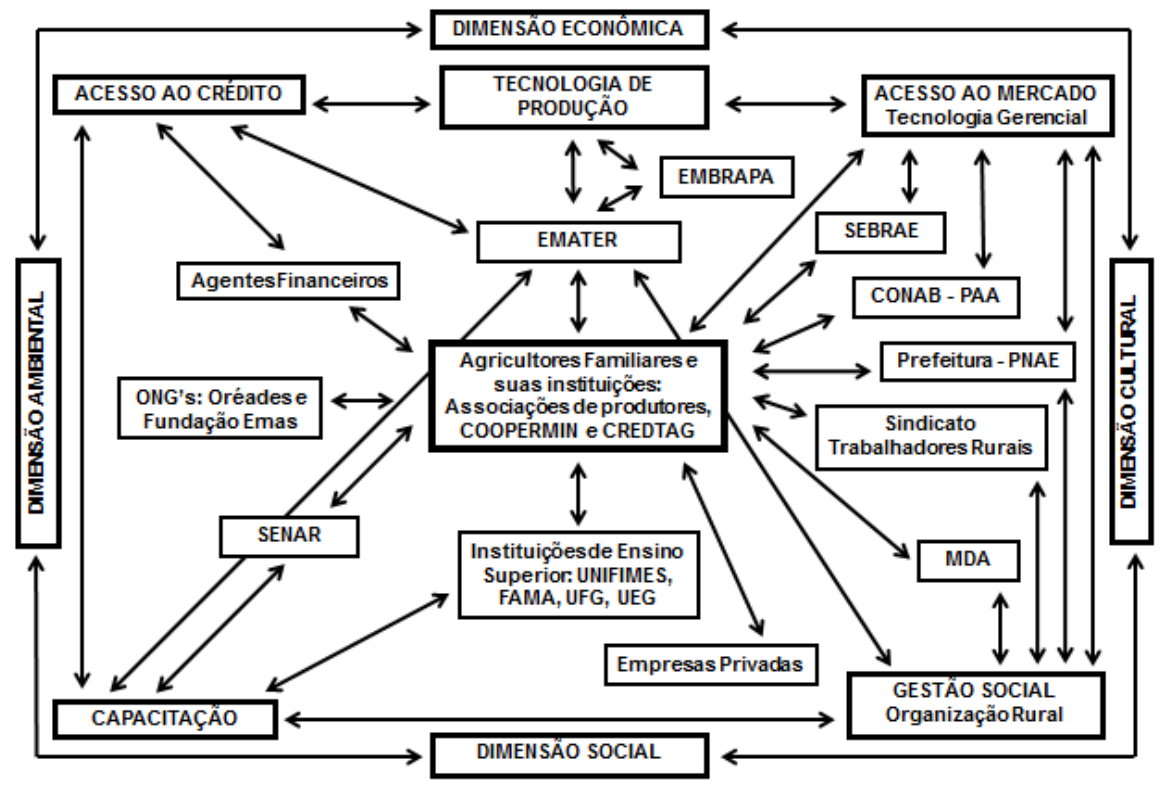

Elaboração: PAULA, M. M. de (2013).

Entende-se que, apoiando a agricultura familiar, a comunidade local possa ter acesso a um alimento de qualidade e com a certeza de origem. Também viabiliza o cumprimento da lei n. 11.947/09 que trata da compra de, no mínimo, 30\% dos produtos da agricultura familiar para a alimentação escolar por meio do Programa Nacional de Alimentação Escolar-PNAE e a participação no Programa de Aquisição de Alimentos-PAA. Isso indica que o agricultor familiar diversifica a produção, aumenta a sua renda e garante a sua segurança alimentar e nutricional. Concomitantemente, o jovem rural vê a possibilidade de continuar a atividade produtiva, não abandonando a propriedade rural.

A comercialização dos produtos da agricultura familiar só é legitimada, com garantia de qualidade, com a certificação dos produtos no Serviço de Inspeção Municipal-SIM e na Vigilância Sanitária. No Município de Mineiros, os produtos de origem animal já são inspecionados pelo SIM, que foi criado pela lei municipal $\mathrm{n}^{\circ}$ 1499/2010 (MINEIROS-GO, 2013). Destaca-se a adequação de algumas queijarias artesanais, que atualmente estão colocando seus produtos no mercado local e na alimentação escolar.

O acesso ao PNAE se deu inicialmente no Município de Mineiros, no ano de 2012, com a comercialização de seus produtos nas escolas municipais. Já o início do PAA deu-se em março de 2013, com a elaboração do projeto encaminhado à CONAB, com início da venda da produção rural em dezembro de 2013.

As principais dificuldades encontradas localmente, de acordo com EMATER (2013), foram, inicialmente, a criação da cooperativa de agricultores, visto que, para acessar o PNAE, a comercialização teria que ser via cooperativa. Esse processo, coordenado pelos técnicos da EMATER e demais instituições da rede de cooperação, durou em torno de dois anos, visto que a cooperativa é constituída por agricultores que moram em suas propriedades e não possuem conhecimento e nem 
Articulação dos atores institucionais no desenvolvimento da agricultura familiar no Sudoeste Goiano

tempo disponível para fazerem a gestão da cooperativa. Nesse sentido, o apoio da prefeitura local foi fundamental para resolver essa questão.

Outra dificuldade encontrada foi na organização da produção, pois, localmente, o mercado é voltado para a pecuária leiteira. Diversificar a produção e acatar as exigências sanitárias com o objetivo de atender à demanda das escolas, entidades sociais e mercado em geral é outro desafio. Trabalhos como os de Agne e Waquil (2011) e Abramovay, Magalhães, Schroder (2010), que apontaram a participação ativa de atores sociais nos processos de desenvolvimento da agricultura familiar, demonstraram que a inclusão produtiva e o acesso aos mercados se dão a partir desse exercício.

Entre as ações que articularam uma parcela representativa de atores sociais, foi a realização das Festas da Semente. O evento, realizado desde 2009, tem por objetivo promover uma reflexão sobre a importância do resgate de espécies tradicioanis e criações de animais que fizeram parte do hábito alimentar de muitas comunidades e que, ao longo dos anos e com os efeitos da globalização, foram se perdendo. Um dos resultados concretos da Festa da Semente foi a criação do Núcleo de Estudos e Pesquisa em Agroecologia, que surgiu em 2010.

Ainda, com o objetivo de organizar a produção dos agricultores familiares ligados à cooperativa, em 2011, foi criado o Programa Municipal de Assistência Técnica-Programa de ASTEC. Por meio desse programa, os técnicos das instituições da rede se colocaram à disposição dos agricultores para atenderem às suas demandas, com foco na agroecologia.

Diante desse contexto, observa-se que as instituições desempenham importante papel nos processos de desenvolvimento. A formação de redes de cooperação pode contribuir com a busca de solução de problemas, com o desenvolvimento da agricultura familiar e, consequentemente, com a melhoria de vida da coletividade, que passa a ter acesso a alimentos saudáveis e com garantia de origem.

\section{Considerações Finais}

A agricultura familiar é responsável pela maioria dos alimentos que chegam à mesa dos brasileiros e foi, por muitos anos, negligenciada pelas políticas de desenvolvimento (IBGE, 2006). Somente a partir da década de 1990, que os agricultores familiares começaram a contar com uma série de políticas públicas voltadas especificamente para desenvolvimento do setor.

Apesar de passados quase 18 anos desde a criação do PRONAF - 1996, observa-se que em muitas regiões do País pouco se viu transformada a realidade do agricultor familiar. Dificuldade de acessar mercados, mesmo tendo acesso ao crédito, dificuldade de manter escala de produção e inúmeros obstáculos para atender às exigências sanitárias no processamento de alimentos.

A partir do entendimento de que o desenvolvimento passa por uma série de fatores, que não só aqueles ligados à disponibilidade de recursos naturais e econômicos, mas também aqueles ligados à interação dos atores envolvidos nos processos, é que se propôs esse trabalho.

A articulação entre os diferentes atores institucionais na área de estudo, no período de 1996, com a criação do PRONAF, até 2013, deu-se por meio da realização 
de ações extensionistas, de assistência técnica e de pesquisa. Essa última, ainda de forma incipiente, mas fundamental, principalmente para subsidiar futuras ações de planejamento. Foram identificadas 32 Instituições envolvidas numa série de ações voltadas para o fortalecimento da agricultura familiar.

Essas informações poderão subsidiar ações locais e regionais na implementação de políticas públicas na escala dos municípios voltadas para o setor e apoiadas nas políticas já instaladas no País a partir da década de 1990.

Os resultados apontam que ações voltadas para a melhoria das tecnologias gerenciais e acesso ao mercado são importantes para o desenvolvimento do setor, visto a potencialidade do mesmo. Isso pode ser endossado com a implementação de políticas de fomento à comercialização, por meio dos programas de mercados institucionais (PAA e PNAE).

Acredita-se que o presente trabalho contribuirá para o desenvolvimento regional, pois considera que os atores sociais constroem relações que são catalisadoras do desenvolvimento local. Sugere-se ainda a aplicação deste estudo em outros municípios, principalmente naqueles que compõem o Território Rural de Identidade Parque das Emas, visto que, a partir da homologação do mesmo, a próxima etapa é a elaboração do Plano de Desenvolvimento do Território. As principais dificuldades nesse tipo de estudo é que nem sempre há informações disponíveis que deem suporte a uma análise ao longo do tempo.

Entende-se que, com os resultados obtidos, as ações possam ser mais eficazes e os atores institucionais tomem consciência do seu papel no processo, contribuindo de forma mais efetiva. Ressalta ainda que, com a presença da rede de cooperação local, ocorra o enfrentamento de um problema comum no País, a descontinuidade das ações quando há mudança dos gestores públicos. Se existe a rede em torno de um objetivo comum, mudam-se os gestores, mas não se muda o curso das ações em andamento. Essa realidade ocorre principalmente quando há instâncias colegiadas nas tomadas de decisão e uma rede articulada em prol de um objetivo comum. Essa realidade pode ser observada no município, visto a presença de várias instituições ligadas em torno da agricultura familiar.

Diante do exposto, considera-se que o estudo tenha cumprido seus objetivos. Torna-se evidente a necessidade de manutenção da rede de cooperação local e ainda a necessidade de se consolidar uma rede regional de cooperação. É notória também a manutenção das instituições que catalisam as ações e, principalmente, a necessidade de realização de pesquisas, no enfoque do desenvolvimento e inovação nos processos ligados à produção agrícola de base familiar. Faz-se necessário um novo olhar dos pesquisadores e suas instituições, das universidades, das agências de extensão rural, que nos últimos anos voltaram suas ações para processos tecnicistas e produtivistas. Torna-se imprescindível um construir coletivo, em que os resultados aparecerão a partir das intervenções e inovações nas mais diversas dimensões do desenvolvimento.

\section{REFERÊNCIAS}

ABRAMOVAY, Ricardo. O capital social dos territórios: repensando o desenvolvimento rural. Revista Economia Aplicada, Ribeirão Preto, v. IV, n. 2, p. 379397, abr/jun. 2000. 
Articulação dos atores institucionais no desenvolvimento da agricultura familiar no Sudoeste Goiano

. Paradigmas do Capital Agrário em questão. 3. ed. São Paulo: Edusp, 2012.

ABRAMOVAY, R.; MAGALHÃES, R.; SCHRODER, M. Representatividade e inovação na governança dos processos participativos: caso das organizações brasileiras de agricultores familiares. Sociologias. Porto Alegre, ano 12, n. 24, p. 268-306, mai/ago, 2010.

AGNE C. L.; WAQUIL, P. D. Redes de proximidade: agricultores, instituições e consumidores na construção dos mercados para produtos das agroindústrias rurais familiares na região central RS. Redes, Santa Cruz do Sul, v. 16, n. 1, p. 149 -171, jan/abr. 2011.

ANDRADE, E. O. de; LUCENA GOMES, F. S. de; CÂNDIDO, G. A. Capital Social como mecanismo para melhoria $S$ nas formas de atuação de cooperativas de Produtores Rurais. G\&DR, Taubaté, SP, v. 8, n. 2, p. 81-106, mai-ago. 2012.

BANDEIRA, P. Participação, Articulação de Atores Sociais e Desenvolvimento Regional. Brasília: IPEA - Instituto de Pesquisa Econômica Aplicada, 1999 (Texto discussão n. 630).

BALSAN, R. Impactos decorrentes da modernização brasileira. Campo-Territórrio. Revista de Geografia Agrária, Uberlândia, v.1, n. 2, p.123-151, ago. 2006.

BAUER, Martin W.; GASKELL, George. Pesquisa Qualitativa com texto, imagem e som. Petrópolis: Editora Vozes, 2008.

BOURDIEU, P. Le capital social. Actes de la Recherche en Sciences Sociales, v.31, p. 2-3, 1980.

BRASIL. LEI N ${ }^{\circ} 11.326$, de 24 de junho de 2006, Estabelece as diretrizes para a formulação da Política Nacional da Agricultura Familiar e Empreendimentos Familiares Rurais. Disponível em: <http://www.planalto.gov.br/ccivil_03/_ato20042006/2006/lei/l11326.htm >. Acesso em: 26 abr. 2012 (2006).

DALLABRIDA, V. R. A dimensão intangível do desenvolvimento: algumas reflexões preliminares. In: BAQUEIRO, M.; CREMONESE, D. Capital Social: teoria e prática. UNIJUÍ: Ijuí, 2006.

EMATER. Relatórios de Atividades 1996 a 2013. EMATER - Agência Goiana de Assistência Técnica, Mineiros-GO, 2013. Documentos Internos.

FRANÇA, C. G. de; DEL GROSSI, M. E.; AZEVEDO MARQUES, V. P. M. de. O censo agropecuário 2006 e a agricultura familiar no Brasil. Brasília: MDA, 2009.

GASTAL, M. L.; ALMEIDA, S. C. R. de; XAVIER, J. H. V. Pesquisa, desenvolvimento e inovação com e para a agricultura familiar. In: OLIVEIRA, M. N. de; XAVIER, J. H. V.; ALMEIDA, S. C. R. de (Editores Técnicos). Projeto Unaí - pesquisa e 
desenvolvimento em assentamentos de reforma agrária. Planaltina: EMBRAPA Cerrados, 2009.

GIORDANO, S. R. Gestão Ambiental no sistema agroalimentar. In: ZYLBERSZTAJN, D.; NEVES, M. F. (Org.). Economia e Gestão dos Negócios Agroalimentares. Editora Pioneira: São Paulo, 2000.

GODOY, Arilda Schmidt. Pesquisa qualitativa: tipos fundamentais. Revista de administração de empresas, São Paulo, v. 35, n. 3, p. 20-29, 1995.

HIGGINS, S. S. Fundamentos teóricos do Capital Social. Chapecó: Argos Editora Universitária, 2005.

HOFFMANN, Ricardo. A distribuição da posse da terra no Brasil de acordo com as PNAD de 1992 a 1999. In: CONCEIÇÃO, J. C.; GASQUES, J. G. (Org.). Transformações da agricultura e políticas públicas. Brasília, DF: Ipea, 2001.

HOFFMANN, R. Distribuição da renda agrícola e sua contribuição para a desigualdade de renda no Brasil. Revista de Política Agrícola, Brasília, Ano XX, n. 02, p. 05-22, abr/jun. 2011.

IBGE. Censo Agropecuário 2006. Agricultura Familiar - Primeiros Resultados Brasil, Grandes Regiões e Unidades da Federação. Rio de janeiro: Instituto Brasileiro de Geografia e Estatística, 2006.

IPEA. Estrutura produtiva avançada e regionalmente integrada: diagnóstico e políticas de redução das desigualdades regionais. Brasília: IPEA - Instituto de Pesquisa Econômica Aplicada, v.2, 2010. 340 p.

MATTEI, Lauro. Impactos do PRONAF: análise de indicadores. Brasília: Ministério do Desenvolvimento Agrário, Núcleo de Estudos Agrários e Desenvolvimento Rural, 2005. 136 p (Nead Estudos; 11).

MINEIROS-GO (Município). Lei Municipal n 1499, de 22 de dezembro de 2010, Institui o Serviço de Inspeção Municipal de Produtos de Origem Animal no Município de Mineiros - SIM - MINEIROS-GO. Disponível em: <http://www.mineiros.go.gov. br/mineiros/index.php\#legislacao.php >. Acesso em: 28 abr. 2013.

MONTE-MÓR, Roberto Luís. O que é o urbano, no mundo contemporâneo. Revista Paranaense de Desenvolvimento. Curitiba, n.111, p.09-18, jul./dez. 2006.

MORAES, L. A. de. Contribuição potencial de atividades produtivas agroalimentares para a formação de um sistema agroalimentar localizado (SIAL), na Região Vale do Caí, RS. In: Simpósio Internacional sobre Desenvolvimento Regional, VI, 2013, Santa Cruz do Sul. Anais... Santa Cruz do Sul: UNISC, 2013. 
Articulação dos atores institucionais no desenvolvimento da agricultura familiar no Sudoeste Goiano

MULS, L. M. Desenvolvimento Local, Espaço e Território: O Conceito de Capital Social e a Importância da Formação de Redes entre Organismos e Instituições Locais. Nova Economia, Belo Horizonte, v. 20, n. 1, p. 11-37, jan-abr, 2010.

NAVOLAR, T. S., RIGON, S. do A., PHILIPPI, J. M. de S. Diálogo entre Agroecologia e Promoção da Saúde. Revista Brasileira em Promoção da Saúde, Fortaleza, v. 23, n. 1, p. 69-79, Fev./Mar. 2010.

PAULA, M. M. de; DIOGO, Alcebíades. CARBALLAL, Manuel R.; GOMES. Marco Antônio F. Realidade Sócio-Econômica das Propriedades Rurais na Região das Nascentes do Rio Araguaia, GO/MT. In: GOMES, M. A. F. (Editor Técnico). Uso Agrícola das áreas de afloramento do Aquífero Guarani no Brasil. Jaguariúna: EMBRAPA - CNPMA, 2008.

PNUD; FJP; IPEA. Atlas do Desenvolvimento Humano no Brasil 2013. Disponível em: <http://atlasbrasil.org.br/2013/o_atlas/o_atlas_>. Acesso em: 10 ago. 2013.

PORTAL DO EMPREENDEDOR. MEI - Microempreendedor Individual. Disponível em: < http://www.portaldoempreendedor.gov.br/mei-microemp >. Acesso em: 06 jan. 2014 .

PORTAL ODM. Acompanhamento Municipal dos Objetivos de Desenvolvimento do Milênio. Disponível em: <http://www.portalodm.com.br/relatorios/1-acabar-com-afome-e-a-miseria/go/mineiros >. Acesso em: 10 ago. 2013.

PUTNAM, R. D. Comunidade e Democracia: a experiência da Itália Moderna. Rio de Janeiro: FGV, 2002.

RAMBO, A. G.; FILIPPI, E. E. Das concepções clássicas à abordagem territorial: para (re)pensar processos de desenvolvimento na agricultura familiar. G\&DR, Taubaté, SP, v. 5, n. 1, p. 121-148, jan-abr. 2009.

REIFSCHNEIDER, F. J. B., HENZ, G. P.; RAGASSI, C. F.; DOS ANJOS, U. G.; FERRAZ, R. M. Novos ângulos da História da Agricultura no Brasil. Brasília: EBRAPA Informação Tecnológica, 2010.

RICHARDSON, R. J. Pesquisa Social: Métodos e Técnicas. 3. ed. São Paulo: Atlas, 1999.

RODER, Elisângela dos S. F.; SILVA, Edna L da. Agricultura familiar e as teses de doutorado no Brasil. TransInformação, Campinas, v. 25, n.2, p. 111-126, maio/ago., 2013.

RODRIGUES, W.; TEIXEIRA, M. C.; SILVA, M. R.; DINIZ, B. C. Capital Social e desenvolvimento regional: o caso do sudeste do Tocantins. BARROS PINTO, Redes, Santa Cruz do Sul, v. 17, n. 1, p. 232-248, jan-abr. 2012. 
SACHS, I. Caminhos para o desenvolvimento sustentável. Rio de Janeiro: Garamond, 2009.

SCHNEIDER, S. Situando o desenvolvimento rural no Brasil: o contexto e as questões em debate. Revista de Economia Política, São Paulo, v. 20, n. 3(119), p. 511531, jul-set. 2010.

SEN, Amartya. Desenvolvimento como liberdade. São Paulo: Companhia das Letras, 2010.

SILVA, J. GRAZIANO da. A nova dinâmica da agricultura brasileira. Campinas: UNICAMP, Instituto de Economia, 1998.

. DEL GROSSI, Mauro; CAMPANHOLA, Clayton. O que há de realmente novo rural brasileiro. Cadernos Ciência e Tecnologia. Brasília, v. 19, n 1, p. 37-67, jan/abr. 2002.

TRICHES, R. M.; SCHNEIDER, Sergio. Alimentação Escolar e Agricultura Familiar: reconectando o consumo à produção. Saúde Sociedade, São Paulo, v.19, n.4, p. 933-945, 2010.

XAVIER, J. H. V.; ZOBY, J. L. F.; OLIVEIRA, M. N. de. Uso do enfoque de P\&D para apoiar o desenvolvimento da agricultura familiar: a experiência dos Projetos Silvânia e Unaí. In: FALEIRO, F. G.; SOUSA, E. dos S. de. Pesquisa, desenvolvimento e inovação para o Cerrado. Planaltina: EMBRAPA Cerrados, 2007.

WANDERLEY, Maria de Nazareth B. Raízes históricas do campesinato brasileiro. Agricultura familiar: realidades e perspectivas. v. 3, p. 21-55, 1999.

ZIEMBOWICZ, J. A.; MAIA, A. DA S.; PEREIRA, P. B.; DIEL N. O.; GOULART, S. P. Sementes Crioulas: segurança alimentar pela diversidade. Revista Brasileira de Agroecologia. Porto Alegre, v.2, n.1, p. 1.073-1.077, 2007.

José Luís Gomes da Silva. Doutor em Ciência - ITA - Professor Assistente Doutor do Programa de Pós-graduação em Administração - Mestrado em Planejamento e Desenvolvimento Regional da UNITAU - gomesdasilvaster@gmail.com

Marcia Maria de Paula. Mestre em Planejamento e Desenvolvimento Regional (UNITAU) - Universidade de Taubaté - marcia@fimes.edu.br 